\title{
Mariano Andreu, col-leccionista, restaurador i creador
}

\author{
Esther Garcia-Portugués \\ Universitat de Barcelona. Departament d'Història de l'Art \\ estgar@gmail.com
}

Recepció: 17/02/2017, Acceptació: 05/05/2017, Publicació: 22/12/2017

RESUM

Un aspecte poc conegut del polifacètic artista Mariano Andreu fou la seva afecció pel món de les antiguitats. De fet, es convertí en un expert en aquest àmbit, com així va quedar enregistrat a la premsa, a la correspondència i, després de la seva mort, a les obres d'art $\mathrm{i}$ als mobles que se subhastaren a la vil·la Tragaviento (Biarritz). Moltes d'aquestes peces provenien de la casa que posseïa al carrer Marbeau de París, també dita casa museu. El present estudi pretén donar a conèixer algunes d'aquestes adquisicions i de l'ús que en va fer, atès que van ser l'origen de noves $i$ imaginatives creacions.

Paraules clau:

col-leccionisme; Mariano Andreu; antiquaris; restaurador; oficis

\section{Abstract}

Mariano Andreu, antique collector, restorer and creator

A little-known aspect of the multifaceted artist Mariano Andreu was his fondness for the antiquarian world. Andreu was an expert in antiquities as evidenced through newspapers, letters and, after his death, the masterpieces (art and furniture) auctioned in Villa Tragaviento, Biarritz. Some of these works came from his house at rue Marbeau in Paris, also a museum house. This paper attempts to shed some light on these acquisitions, such as when they were purchased and how the artist used them, as they marked the beginning of new and imaginative creations.

Keywords:

collecting; Mariano Andreu; antiquarian; restorer; craft 
$\mathrm{M}$ ariano Andreu, a més d'artista, va ser un home culte amb unes preferències estètiques cultivades al llarg de les seves visites a museus i antiquaris. Producte d'aquests hàbits, s'afeccionà a col-leccionar mobles $\mathrm{i}$ a cercar objectes que recreaven un ambient específic que li permetien reviure un passat que ja formava part del seu record. Aquest ambient es reflectí tant en el seu art com en els cercles culturals i d'amistat en els quals es va moure. També configurà un món molt particular a les cases on va viure.

Entre les diverses habilitats que tenia, hi havia la de ser un bon artesà, ja que reparava, reconstruïa $i$ fins $i$ tot confeccionava els artístics marcs que havien d'ornamentar les seves obres més preuades. Fent un recorregut per la seva trajectòria de creació, trobem nombrosos exemples que testimonien com aquesta afecció anava més enllà de la de collleccionista.

Atret per la composició, la perspectiva, el moviment, la vida, l'expressió i el ritme de Diego Velázquez, va ser un expert en la pintura del famós sevillà, com també en els bodegons barrocs, encisat per la manera com els objectes hi eren disposats i elevats a la categoria de protagonistes. També va ser un estudiós dels ambients culturals de les ciutats estat del Renaixement, on tenien cabuda totes les arts, i de l'esperit galant de la cort francesa plasmada en l'obra de Watteau, uns referents estètics i visuals, festius i excessius en el gaudi que Andreu trobà en diferents colleccions, com a la Soane Collection (1907) o al Kensington Museum (1957). Configurà el seu propi món en el qual barrejava la riquesa, l'elegància, la bellesa i la classicitat, entesa com a equilibri formal en què l'arquitectura i la figuració responien a uns cànons de perfecció dins la distorsió creativa, en la línia de la maniera de Miquel Àngel i del Greco. Per ell res era gratuit, tot tenia un sentit en la seva composició, que ordenava com si es tractés d'un escenari on succeïa el més important de la vida.

A aquesta visió especial del món contribuí la casa on va viure la infantesa, que, en Empreintes, les seves memòries, la reconstrueix i la converteix en un habitatge ple d'objectes i de mobles. La visita al Museu del Prado i els successius viatges a Londres i, després, a diverses ciutats italianes van ser fonamentals, perquè li van permetre observar i estudiar, si així volem dir-ho, d'una manera autodidacta les obres dels grans mestres de la pintura. La formació reglada en diverses escoles convertí Andreu en un gran artista, però, per damunt de tot, esdevingué un amant de l'objecte que colleccionà, restaurà i fins i tot ideà.

L'obra Empreintes, la premsa i la correspondència són les fonts que comenten l'atracció que sentí per visitar col-leccions, antiquaris, museus i botigues de tot tipus d'objectes. També la premsa i les fotografies del seu taller estudi al carrer de Roger de Llúria número 53 i de les cases a París i a Biarritz n'illlustren l'activitat colleccionista. Algunes de les peces que va adquirir es converteixen en testimonis de la restauració i de l'adaptació en algunes de les seves obres finals. L'inventari dels mobles, dels quadres i dels objectes que van ser subhastats després de la seva mort també corrobora aquesta afecció. En conjunt, es tracta d'una informació recopilada en aquest estudi, a fi de mostrar un Andreu col-leccionista, restaurador i assidu visitador de museus, antiquaris i altres colleccions.

\section{Col·leccions, museus i antiquaris}

Des que les acadèmies de belles arts es disseminaren per Europa durant el segle de la Illustració i, sobretot, quan la formació d'artistes 
i literats, a més de l'aristocràcia, quasi obligava a realitzar el Grand Tour, tot artista que s'apreciés o que volgués conèixer què s'havia fet $\mathrm{i}$ quines tendències estètiques es prioritzaven a Europa en aquell moment havia de viatjar. Aquest seria el cas d'Andreu, que, al començament, compaginà la seva formació amb Laureà Barrau, Alexandre de Riquer i Francesc A. Galî i, més endavant, al Cercle Artístic de Sant Lluc i al Cercle Artístic de Barcelona amb viatges destinats a visitar museus, col-leccions i antiquaris d'arreu d'Europa.

Aquests viatges formatius el convertiren en un expert coneixedor de diferents tendències $\mathrm{i}$ estils. Primerament, visità el Museu del Prado l'any $1905^{1}$, on estudià els grans mestres de la pintura i se sentí especialment atret per l'obra de Velázquez i la dels pintors de bodegons dels segles XVII i XVIII. Després, amb només I 9 anys, marxà a Londres, il-lusionat per aprendre la tècnica de l'esmalt sota el mestratge d'Alexandre Fisher i l'Escola Arts \& Crafts. Fixà la seva atenció especialment en els edificis històrics reconvertits en botigues luxoses, com l'antiga casa de Lord Byron. Freqüentà el món dels antiquaris en la zona situada entre els carrers de Gate Street i Humbles, on trobà tota mena d'objectes (capses d'orfebreria, nines i sobretot el cristall tallat de Rowlandsons). Fou un visitant assidu de la Soane Collection i dels establiments que mostraven o que venien tot tipus d'objectes com ara màscares, pipes, espases, papallones i globus, activitat que potencià el seu afany de colleccionista ${ }^{2}$.

L'any I9I I tornava a Londres, aquesta vegada per perfeccionar la tècnica del gravat i de l'esmalt amb el seu amic Néstor Martín Fernández de la Torre (I886-I972). L'any següent era a París, on residia un altre amic seu, Ismael Smith Marí (I886-1972), pensionat per l'Ajuntament de Barcelona. Després, emprengué un viatge per Itàlia, que repetí al cap de pocs mesos, on va conèixer la seva futura esposa. La documentació el situa entre els anys I9I 2 i I9I 3 a les ciutats de Bolonya ${ }^{3}$, Florència, Rímini, Verona ${ }^{4}$ i també a Baviera ${ }^{5}$.

El mes d'octubre de I9I3, de nou a París, es casava $i$, a finals de novembre, el matrimoni passava uns quants dies a Londres de viatge de noces. En una entrevista que fou publicada a $E l$ Día Gráfico, el mateix artista destacava alguns indrets de la ciutat que encara conservaven l'elegància d'acord amb el seu gust estètic, que alhora fomentaven la seva afecció, aleshores compartida amb la seva esposa, de visitar antiquaris i botigues, com la de Lock, a St. James Street, o la de passejar per la zona freqüentada pels dandis a Old Bond Street ${ }^{6}$.

A partir de 1915, aquesta afecció comuna per col-leccionar està documentada, quan el matrimoni s'adjudicava peces d'antiquari a la primera d'una sèrie de subhastes d'objectes d'art antic que s'organitzaren a la galeria Dalmau'. En el mes d'octubre, Vell $i$ Nou es feia ressò de la seva presència en aquesta activitat: «el delicat artista en Mariàn Andreu ha fet varies compres, podent remarcar, com a més interessant, un capitell i un cap romà» ${ }^{8}$. Justament, Andreu cedí aquestes dues peces al Museu Arqueològic de Mataró, on s'exhibeixen i són identificades com el retrat de Faustina Menor i un capitell corint procedents de la villa romana de Torre Llauder ${ }^{10}$.

L'afecció de visitar museus, assistir a subhastes $i$ adquirir peces d'antiquari el convertiren en un expert en objectes d'art. Anà sovint a Madrid i es relacionà amb crítics, restauradors i collaboradors del Museu del Prado, els quals apreciaren els seus coneixements. Un viatge prou illustratiu de la seva estada a Madrid succeí l'any I952, quan, després de quinze dies, manifestava «charmants y estic charmà [sic] de l'arquitectura del Prado» i explicava a Manuel Rocamora quina era la seva opinió sobre el cap que Salomé portava a la safata. Segons el seu parer, corresponia al retrat de Carles I «[...] el decapitat per en Cronwell» $\mathrm{i}$ hi afegia que formalment semblava el Crist de l'escola de Philippe de Champagne. Per aquest motiu es posà en contacte amb Maria Caturla «Señora altament sensible y de molt talent amiga de Sanchez Canton, y molt considerada per la direcció del Prado» per demanar-li la impressió i l'opinió sobre aquesta pintura. Andreu també suggeria a Caturla la necessitat de col-locar i atribuir correctament el quadre, ja que considerava que podria ser «una de les curiositats del museo que la dita pintura, té tots els aspectes de l'école de Nancy y qu'es mes que tot germanic». A la carta dirigida al seu amic, hi afegia que Caturla admetia que possiblement fos una obra anglesa ${ }^{11}$.

Uns quants dies després, de nou escrivia a Rocamora fent detall de diverses obres que l'havien seduït a Madrid, per exemple: «la Veronica del Greco à Casa la Maria Caturla, c. Fortuny 45 , el cuadro mes magic qu'he vist, pur, sense vernis, intacte ab el seu marc fi - se [sic] present qu'el Greco l'acaba de deixar de pintar [...] y'l supréme color. Negre y blanc». Es refereix a ella com la «pitonisa del Prado i es arcangel conseller», i sobre el quadre de Salomé «atribuit a l'escola flamenca Prado ${ }^{\circ}$ 1940. Sala LXX planta baixa "Degollacion de San Juan Bautista" I4 metros de llarc per 3,50 alt.-», opinava que era de l'escola de Nancy. Per tant, a continuació explicava:

Es cuadro a ferne un llivre ab ioo reproduccions de fragments. Es un cuadro que fa 4 anys vareig estudiar pam per pam ab una toballola mullada per a netejarlo amb el per- 


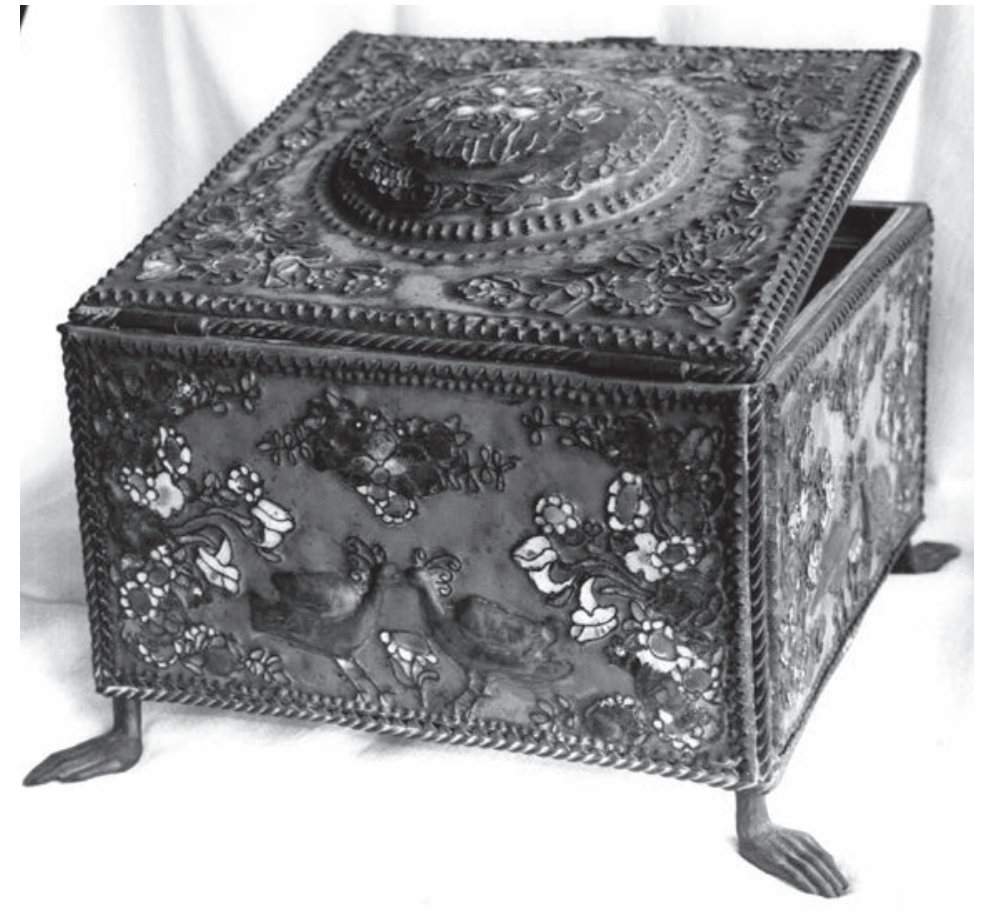

Figura 1.

Mariano Andreu, Der Frühling (c. 1912), esmalt alveolat i mans de bronze, $19 \times 24 \times 24 \mathrm{~cm}$. Barcelona, Arxiu Fotogràfic Mariano Andreu (AFMA), 1912, 72.

mis de Sanchez Canton.- Ne vareig parlar a la Señora Caturla cuadro qu'ella coneixia y va suggerar que y habien coses que podrien esser ingleses.

Després d'aquesta faceta, que se'n podria dir de pràctica restauradora, $\mathrm{i}$ de veure de nou el quadre, comentava:

[...] crec que podria altament interessante y m'agradaria ma diguessis que t'ensemble.La Salomé que porta el cap del Sant Joan sobre una safata, trovant que podria esser el cap de Carlo I d'Inglaterra [...] opinió que no reposa ab res puig el dit cap se sembla a ton Christ de Philippe Campagne y no te res de Charles I $^{12}$.

En referència al tema que ens ocupa, el més interessant d'aquestes cartes és la relació que va mantenir amb Maria Caturla i Sánchez Cantón durant anys, ja que el quadre, tal com escriu Andreu, l'havia fins i tot netejat abans d'aquest viatge. D'aquesta manera es confirma que, a més de ser un apassionat per l'obra i per l'objecte d'art, era, alhora, un investigador dels grans mestres de la pintura que mostrava predilecció pel Greco i per Velázquez, però que també estava interessat per altres escoles i tendències.

Uns quants anys més tard, quan va ser sollicitat per John Gielgud a Londres a causa de l'èxit que estava obtenint amb l'obra teatral Much Ado about Notbing i per la seva aportació a l'estrena de The Trojans, explicava a la seva esposa el viatge que havia fet a Oxford i Cambridge. Del seu pas pel Kensignton Museum, en destacava: «Combien de choses merveilleuses, j'ai vú aujourd'hui! Deux guardi de la plus merveilleuse qualité, des meubles français et anglais! Que peut restes pour demain de tout ce qui on crée dans l'art soit eu meuble, peinture, robes et bijoux?» ${ }^{13}$. Com quan era jove, continuava la seva atracció pels objectes, els vestits i tota obra que li recordés un passat d'exquisidesa, elegància i festa on totes les arts tenien cabuda.

Els seus coneixements sobre pintura, especialment espanyola, així com sobre altres disciplines artístiques van ser reconeguts i recompensats per l'Acadèmia de les Belles Arts de París, on va ser admès com a membre l'any I953 i nomenat Membre associé de l'Academie de Beaux Arts l'any i958, un reconeixement acadèmic que rebien pocs estrangers ${ }^{14}$. Aviat actuà com a representant de l'Institut Francès quan fou convocat per homenatjar Velázquez a la Real Academia de Bellas Artes de San Fernando i a la casa del pintor durant els dies 7, $9 \mathrm{i}$ Io de desembre d'aquell mateix any. Durant les jornades, hi van tenir lloc diverses conferències i col-loquis. La contribució d'Andreu, titulada «Velázquez, sus préstamos bien pagados», fou agraïda per l'acadèmic M. Réau en la comunicació «Échanges de Vues». D’Andreu se'n valorà especialment el coneixement dels quadres d'artistes que van precedir Velázquez i la dels seus contemporanis, paraules que l'identificaven $\mathrm{i}$ que el situaven com a expert del pintor homenatjat $\mathrm{i}$ de la pintura renaixentista $\mathrm{i}$ barroca $^{15}$. Guillermo Díaz-Plaja rememorava orgullós haver abraçat aquest català universal. El descrivia com un personatge de port quevedià, vestit d'or i verd quan representava l'Institut Francès ${ }^{16}$, indumentària molt apropiada per a l'acte $\mathrm{i}$ que alhora responia al càrrec oficial que representava.

\section{Destí de les peces d'antiquari (restauració, col·lecció i creació)}

Algunes de les peces que va adquirir a antiquaris serviren per guarnir algunes de les seves creacions o bé foren motiu d'inspiració per elaborar magnífics i complexos marcs. També està documentada la participació d'alguna obra en mostres com ara l' «Exposición de retratos y dibujos antiguos y modernos» que organitzà l'Ajuntament de Barcelona l'any i9ro, a la qual va contribuir amb el Retrat d'Alenza de la seva 
collección ${ }^{17}$. Un mes abans, Andreu havia escrit al seu amic Néstor aportant dades sobre aquest mateix quadre: «Mando el retrato antiguo que compré en los encantes, et recordes? a la exposición de retratos lo he enmarcado en la cornucopia del taller y está divino me parece tendrá éxito pido I 5000 pesetas nada una friolera» ${ }^{18}$. També li explicava que visitar els Encants i els antiquaris constituiia una de les seves darreres afeccions.

Un altre exemple, en aquest cas d'aportació d'obra, concretament al Museu Municipal de Sitges, es produí el i9 de febrer de I913, quan se celebrà un banquet en honor a Santiago Rusiñol. Entre el centenar de comensals procedents del món empresarial, de la política, del món editorial i de l'art, hi havia Andreu, qui regalà, talment com altres «[...] obgectes pel futur Museu Municipal» ${ }^{19}$.

Andreu sempre es caracteritzà per realitzar un treball manual, pacient $i$ artesanal, faceta que valorà Joaquim Folch i Torres (Jordi Flama) a La Veu de Catalunya, quan el Faianç Català li realitzà una monogràfica ${ }^{20}$. Aquesta habilitat li serví per restaurar peces que s'havia adjudicat en subhastes o bé que havia adquirit a antiquaris. Així l'artista seguia la màxima d'Oscar Wilde, que sintetitzava la filosofia del moviment Arts and Crafts, basada en la defensa del treball artesanal: «El nuestro ha sido el primer movimiento que ha aunado a artesanos y artistas, pues recordad que separando el uno del otro arruinaréis a ambos; a uno le robáis todo motivo espiritual y todo el deleite imaginativo, al otro le aisláis de la verdadera perfección técnica» ${ }^{21}$.

Objectes com ara cofres o joiers (figura I ) $^{22}$ i plats decorats són els exemples més clars del treball realitzat en diferents tècniques aplicades a l'esmalt, camp llevat, caboixons, cuirs gravats i coure repujat. Un treball que s'ha de vincular amb les obres que va observar $i$ analitzar a museus $\mathrm{i}$ antiquaris com a base $\mathrm{i}$ motius d'inspiració. Algunes d'aquestes peces tan elaborades $\mathrm{i}$ interdisciplinàries van ser subhastades quan va morir ${ }^{23}$. Inspirant-se en obres d'antiquari, en algunes hi incorporà marcs antics, com ara, per exemple, a L'esperit del mal (I910) (figura 2), un esmalt de petites dimensions que així adquiria una gran envergadura. Aquesta pràctica de reconstrucció fou habitual al llarg de la seva trajectòria artística, com a Antíop (1946), un altre exemple de la continuitat en la cerca de peces d'antiquari que restaurava i que incorporava a les seves creacions amb un marc sumptuós que fes honor, en aquest cas, a una obra realitzada sobre pedra, gravada amb un grattage molt avantguardista ${ }^{24}$, o bé la tasca d'elaborar un petit moble o tríptic per poder transportar l'esmalt Sensus (1910) ${ }^{25}$.

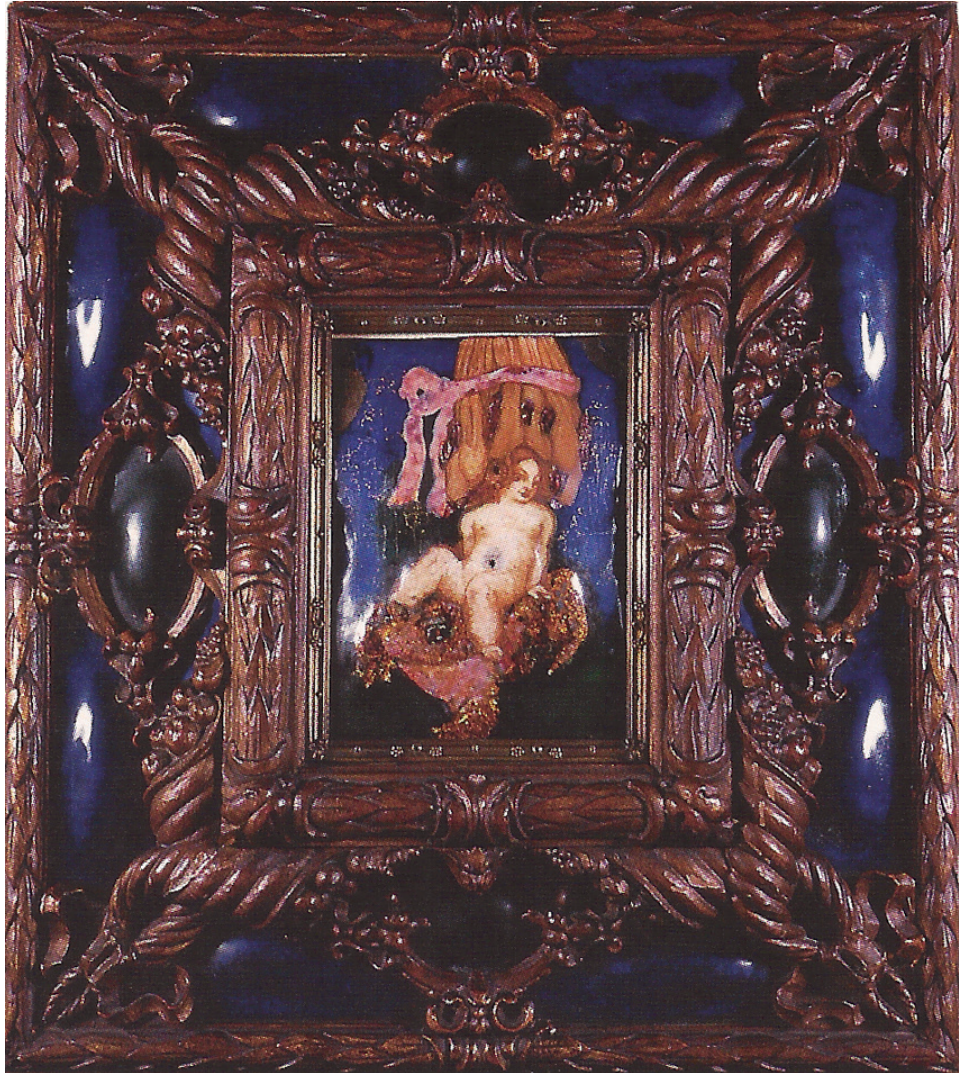

Figura 2.

Mariano Andreu, L'esperit del mal (1910), esmalt, $17 \times 12,5 \mathrm{~cm}$. Barcelona, col-lecció privada.

Aquesta praxi d'artífex la compaginà a l'inici de la seva faceta més decorativa i creativa amb dissenys que singularitzaven cadascuna de les peces. Utilitzà materials diversos que perllongaven l'espai, configurant un escenari on l'artista exhibia el motiu o tema principal del quadre. En aquest darrer grup, hi trobaríem les pintures, els guaixos i els dibuixos més interessants des del punt de vista compositiu, com ara Répétition de Danse (1930), Hortanse's Bar (1930), Joie Géométrique (1930), Costume Gavotte de Prokofieff per Alanova (193I) $)^{26}$, Rybtm désaxé (193I), L'écuyère (1933) ${ }^{27}$ o Crist de l'amor i el perdó (1945), amb uns marcs imponents de collage fets de diversos materials.

Davant d'aquestes elaboracions fantasioses dels marcs, és obligatori que ens aproximem als miralls i a uns altres objectes decoratius que foren reproduits en revistes de moda i de mobles com ara Art et Décoration, Town E Country, L'Elégance Française o Le Figaro illustré. Treballs artístics que constaten que mai oblidà la faceta artesanal empresa als seus inicis artístics i que, alhora, mostren un artista molt imaginatiu, pacient i metòdic, com es pot comprovar al Mirall que se subhastà a Biarritz (figura 3$)^{28}$. De passada, li permetia explorar i manipular diversos materials, a fi d'aconseguir un treball 


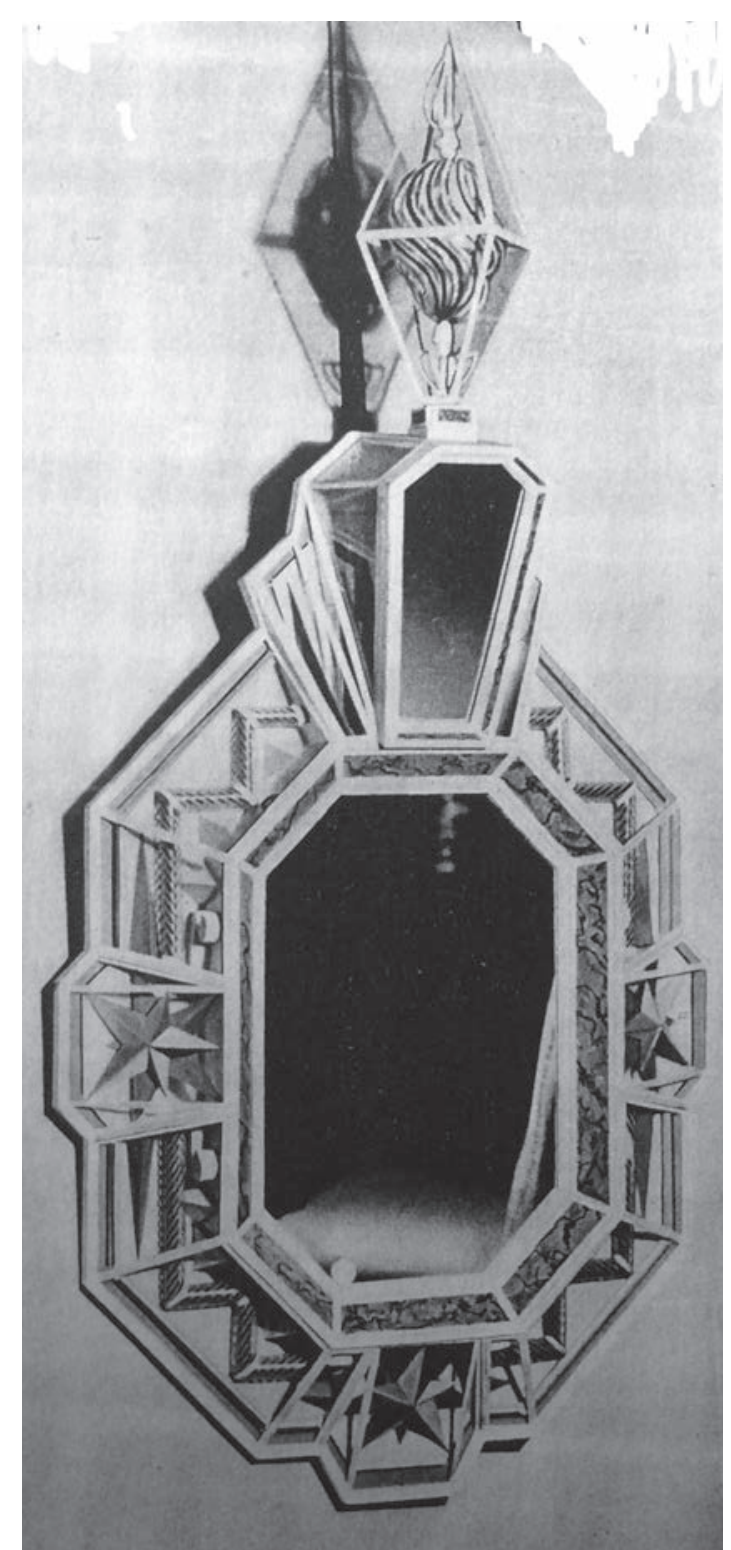

Figura 3.

Mariano ANDREu, Mirall amb pinacle, assemblage de matérieux divers (c. 1935), $148 \times 74 \mathrm{~cm}$. Arxiu Fotogràfic Mariano Andreu (AFMA), 1937, 71.

exquisit que explica l'èxit de l'exposició Miroirs et poupées de Mariano Andrë̈, que se celebrà a la Galerie Serge Roche el mes de maig de i935. A la galeria, s'hi exhibiren peces realitzades en paper maixé i vidre engomat, amb la qual cosa demostrà que era un mestre de la papiroflèxia ${ }^{29}$. La premsa destacà de la mostra la magnífica $\mathrm{i}$ complexa elaboració dels miralls, uns objectes decoratius molt valorats pels parisencs, faceta artística a la qual es dedicaren un bon nombre d'artistes ${ }^{30}$.

Andreu sempre s'inclinà a recrear un ambient selecte, únic, a través d'objectes personalitzats fora del que representava la reproducció mecànica $\mathrm{i}$ industrial que homogeneïtzava els espais i la vida. Per tant, no és estrany que s'erigís en un defensor plàstic de l'objecte per la bellesa i pel seu segell personalitzat. De nou, Oscar Wilde tornava a ser el seu referent, i, com ell, no estava en contra de la maquinària, sinó de l'home que pretén utilitzar-la per fer allò que només pot ser valuós quan es produït per les mans i el cor ${ }^{31}$. Aquest interès no sols el situà en la línia de recuperar els oficis, que Arts and Crafts i especialment Oscar Wilde defensaven, sinó també dins l'esperit del noucentisme com a senya d'identitat.

Aquest treball artesanal i la seva habilitat foren definits perfectament per Henri de Regnier de l'Académie Française, autor del catàleg de l'exposició «Miroirs et poupées de Mariano Andreü» ${ }^{32}$. Regnier, després de fer un breu repàs biogràfic de l'artista, en destacava:

Ses mains attiraient l'attention. On les devinait merveilleusement adroites et sensitives, aptes à palper une étoffe, à caresser un relief, à manier le pinceau, la pointe, l'ébauchoir aussi bien qu'à ciseler le métal ou à froisser le papier, habiles à toutes les techniques, des mais d'artiste et d'artisan!

Sobre el seu treball creatiu en fer quadres i miralls, hi afegia:

Ces cadres sont le dernier amusement d'Andreü. Sur des armatures de bois, avec des papiers de couleurs, du carton doré et argenté, de la colle, des fragments de verre, il a composé d'étonnantes bordures, d'une variété et d'une ingéniosité incomparables où l'on peut enfermer une peinture, un dessin, un miroir.

El crític Denis Bourdet es referia a aquest treball com una tasca laboriosa i enginyosa i associava Andreu a un veritable artífex que anava molt més enllà. El convertia en arquitecte quan recollia les paraules de Henry de Montherlant:

Tous ces tableaux son encadrés avec une ingéniosité étonnante. Le peintre confectionne lui-même ses cadres, et les orne de fragments de verre, de papiers argentés, coloriés ou dorés. Le goût qu'a cet artiste de fabriquer de ses mains est tel, que Montherlant prétend que la belle maison qu'il possède à Biarritz, Andreu a dû la construiré lui-même ${ }^{33}$.

De fet, el disseny de la casa, la distribució de l'espai i tota la decoració foren ideats per ell.

Per tant, podem dir que el costum de visitar museus i colleccions, així com l'afecció d'adquirir peces d'antiquaris, es reflectí en la transformació de les seves cases, moltes vegades 


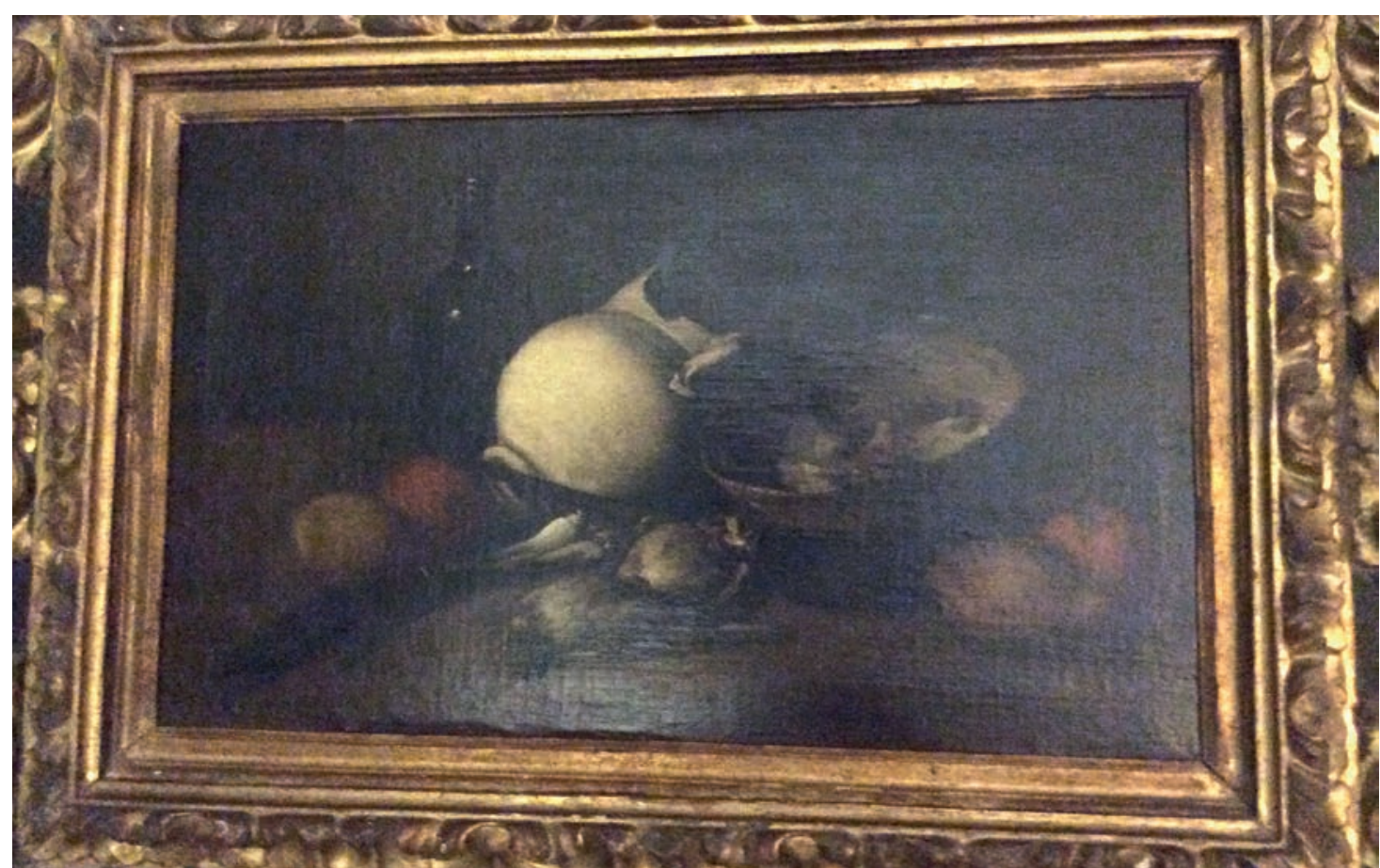

Figura 4.

Anònim atribuït a Velázquez, Bodegó (segle XviI), oli i tela. Barcelona, col·lecció privada.

considerades veritables museus pel seu contingut en valuoses peces, una gran quantitat de les quals foren subhastades quan l'artista va morir, com ja hem esmentat més amunt.

\section{Les cases i els estudis com a museus}

El fons documental i fotogràfic recopilat de l'artista, a més de les fonts bibliogràfiques, permeten classificar les cases on va viure i els seus estudis taller com a petits museus, en els quals no sols s'exhibien o es guardaven peces seves, sinó també peces adquirides en subhastes $i$ antiquaris.

Ignasi Mallol (I 892-1940), quan es traslladà al taller que abans havia estat el de Mariano Andreu al carrer de Roger de Llúria, comentà a Francesc Vayreda que va ser un dels més «hermosos de Barcelona», com ja deuria saber, i hi afegia que comptava amb ell per compartir el lloguer ${ }^{34}$.

L'arxiu fotogràfic de l'artista reprodueix els escrits sobre les impressions rebudes pels crítics i periodistes d'aquella època. Segurament, aquestes apreciacions poden ser molt diferents de les actuals, una realitat que caldrà tenir present a l'hora d'interpretar les fotografies com a testimonis dels seus referents i de les seves afeccions. Un cas seria la reproducció d'una Menina en el seu estudi taller de Barcelon $\mathrm{a}^{35} \mathrm{o}$ bé alguns bodegons, peces d'antiquari que col-leccionava, com l'obra triada (figura 4), dos exemples prou il-lustratius de la seva preferència estètica pel període del barroc, especialment quan es tractava de natures mortes ${ }^{36}$, i de la seva afició per visitar antiquaris. Les fotografies, però també l'inventari de la subhasta de les seves pertinences, palesen el seu criteri per adquirir mobles bons, de períodes que anaven des del segle XVI fins al segle XIX, els quals no eren considerats una mera decoració per l'artista, sinó que els utilitzava a diari, com el llit o l'escriptori al seu dormitori, mobles als quals dedicarem una atenció especial. Tot i que, en general, les cases i els estudis presentaven un aspecte abarrocat per la quantitat d'objectes exposats, aquests més aviat oferien un ambient de museu, però, això sí, de museu funcional i pràctic. La premsa, en molts casos en format de reportatges, recollia algunes d'aquestes característiques, tant dels edificis com dels seus interiors i dels seus entorns, fonts bibliogràfiques molt útils que complementen les fonts documentals i l'arxiu fotogràfic.

Respecte a l'edifici i, concretament, a l'exterior de la casa del carrer de Marbeau, Blanco y Negro publicava: «Mucho hombre, mucho hombre, Mariano Andreu, Monte-Cristo ha hablado en Blanco y Negro de los esplendores del hotel de Andreu, cerca del Bois», l'autor considerava la casa un hotel i una «[...] mansión de arte» que «representa la colaboración del esfuerzo de una rigurosa artesanía $»^{37}$. Denis Bourdet, a La Revue de París, escriví: «Il habite depuis trente-cinq ans dans une rue tranquille 


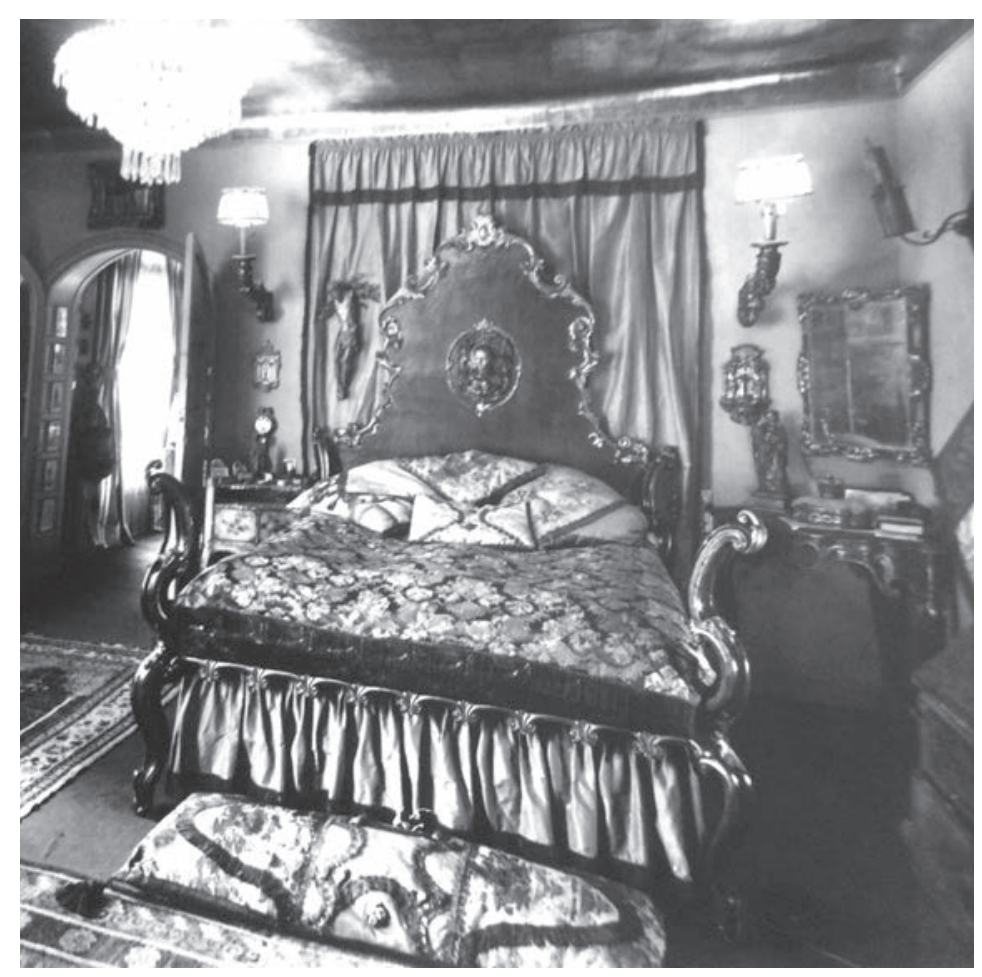

Figura 5.

Fotografia del llit al dormitori del matrimoni Andreu. Barcelona, Arxiu Documental Mariano Andreu (ADMA), 1925-1935.

de Passy, une petite maison rouge d'un style I9ro qui la rend assez semblable a beaucoup d'autres de ce quartier, mais la porte franchie, on se trouve en Espagne» ${ }^{38}$.

Sobre la vil·la Tragaviento a Biarritz, Pierre Espil en destacava la sumptuositat:

[...] sur le plateau du Phare, tout pres de l'hôtel Régina. Ce prestigieux décorateur en a fait une sorte de musée, mieux encore un palais de rêve où totu, jusqu'aux mondres détails, prote le cachet de son style prope. Avec son patio aux murs blancs, au gazon velouté, son jardin en pente vers la mer dont les escaliers sont décorés de galets et de coquilles d'huîtres, ses cambres de parade aux lits à bladaquins, «Tragavient» c'est un "opéra fabuleux» composé par un artiste dont l'imagination a été électrisée par l'étincelle magique du surréalisme ${ }^{39}$.

Més extensament, els diaris i les revistes van dedicar més espai a recrear la impactant visió dels interiors per així donar a conèixer l'àmbit privat de l'artista, cosa que, en gran part, es devia a l'èxit europeu que havia assolit darrerament. La revista $D^{\prime}$ Ací i d'Allà publicava una espècie de reportatge de la casa de París que ressaltava, d'una part, l'atmosfera dels establiments dels antiquaris que emanava dels mobles i la decoració, i, de l'altra, molt escenogràfica, que traslladava els visitants a espais que recreaven diversos segles anteriors, atès que amb «un sostre generosament alt dona un aire magnífic a aquest hall i suavitza amb una discreció insuperable l'agombolament de mobles, pintures $\mathrm{i}$ objectes preciosos que poblen l'estada».

En conjunt, tant les adquisicions com les seves obres proporcionaven una visió de l'artista envoltat d'un gran nombre de peces disposades arreu com si d'un museu es tractés. Per exemple: del dormitori, en destacava «un llit barroc d'exquisit dibuix $\mathrm{i}$ un armari venecià lacat en vermell ${ }^{40}$. El llit (figura 5), que duia el número 276 a la subhasta de Biarritz, va ser catalogat com a «Rar elit [sic] en bois laqué bleu, vert et or, à montants tournés partiellement dorés; dosseret découpé orné d'une peinture représentant le mariage de la Viere entre des guirlandes et rinceaux. Travail catalan du XVIIIe siècle» $(2 \times 2, \mathrm{I} \circ \times \mathrm{I}, 68)$. L'escriptori $^{41}$ (figura 6), que consta al catàleg amb el número 245, figurava com un «Important meuble scriban en bois laqué vert orné de grotesques, oiseaux et branchages dorés; fronton découpé, surmontnat quatre tiroirs et deux portes vitrées, l'abattant découvre douze tiroirs et une niche centrales. La partie basse ouvre à cinq tiroirs garnis de poignée de tirage mobiles» $\mathrm{i}$ era catalogat com a espanyol del segle XVIII $(2,70 \times$ $\mathrm{I}, 32 \times 0,66)^{42}$. De les descripcions publicades a l'article de D'Ací i d'Allà, se'n desprèn una certa melangia de l'artista pel seu passat barceloní, mentre que l'abarrocament de l'espai respon a la idea de com l'artista revivia la visita que realitzà a la col-lecció Soane de Londres l'any 1907, tal com s'expressà a les seves memòries ${ }^{43}$.

Denis Bourdet també incidia en l'ambient:

La pénombre d'un grand hall où court à mi-hauteur une galerie, laisse apercevoir un encombrement d'objets d'art ibériques, de meubles baroques, de coffres sculptés, de brocarts, de statues de bois peintes, de lustres, de cadres et de miroirs anciens ${ }^{44}$.

La premsa sintetitzava com era la casa de $\mathrm{Bi}$ arritz quan es produïren dos fets remarcables: la donació del Crist (1945) a la catedral de Baiona, al sud de França, i la mort de l'artista (1976). Correspon a un període en què la seva fantasia es desenvolupà extraordinàriament, il·lusionat per convertir la casa en un lloc de trobada d'artistes i d'amics, sobretot després que enviudà l'any i959.

Amb motiu de la donació del quadre del Crist, el diari Basque Eclair descrivia Tragaviento així: «face à l'océan, au centre d'un jardin accrocé à la roche, fenêtre de soixante mètres sur l'imensité marine». La casa era esmentada com 
si fos un veritable museu, on els amics podien admirar totes les meravelles col-leccionades al llarg dels seus viatges i de la seva existència. Entre les obres relacionades, hi figuraven «trois tableaux et dessins de l'époque bleue de ce génie», Picasso, i un Velázquez que va comprar a un antiquari sevillà. «Dans les vitrines, des émaux anciens, sur les murs et dans des encoignures de bois sculptès, certains du XIIe siècle et tant d'autres pièces précieuses» ${ }^{45}$. També, quan va morir, Pierre Espil publicava una breu biografia en la qual feia un esment especial a com era «villa Tragaviento non loin du phare», que era qualificada com una de les més belles residències de la regió. La catalogava de palau

Musée intime regorgeant de pièces sans prix, palais de songe au péril de la mer. La tout porte la marque d'una imagination electrisée par l'étincelle du surréalisme: patio aux murs blancs escaliers descendant vers les flots et décorés de coquilles d'huîtres, chambres de parade aux lits à bladaquins, salon qu'une immense baie vitrée transforme en cabine de naviere ${ }^{46}$.

Uns quants anys abans, el mateix autor havia escrit:

Le maître nous reçoit dans un vaste salon dont tout un côté n'est qu'une vaste baie vitrée donnat sur l'océan. On se croirait dans una navire et la lumière crue, les fastes écumeux de la mer, «toujours recommencée», confèrent aux trésors artístiques rassemblés dans la pièce comme une dimension nouvelle, un climat de pureté, et de grandeur qui leur convient â merveille ${ }^{47}$.

De l'estudi taller íntim $\mathrm{i}$ alhora pràctic amb un sostre elevat a Barcelona, destinat a rebre amics i a encabir la mufla, passem a uns estudis taller vinculats amb la natura, especialment a Biarritz. A París, un petit jardí separava la casa del taller. Així el descrivia Denis Bourdet:

Un petit jardin dalle de briques le sépare de la maison d'habitation, et cette haute salle n'en a plus l'atmosphère de luxe compact, mais celle du désordre qu'animent de multiples travaux. Sur une vaste table, on voudrait dire un établi, une pierre lithographique voisine avec des burins, des ébauchoirs, des scies à découper, des pots de peinture, d'acide et de colle, des feuilles de cuivre, des planches, des toiles, des papiers, du carton, de crayons, des pinceaux, une palette et des tubes de couleurs. Dans ce fouille, Andreu a parfois de la peine à retrouver ce qu'il cherche ${ }^{48}$.

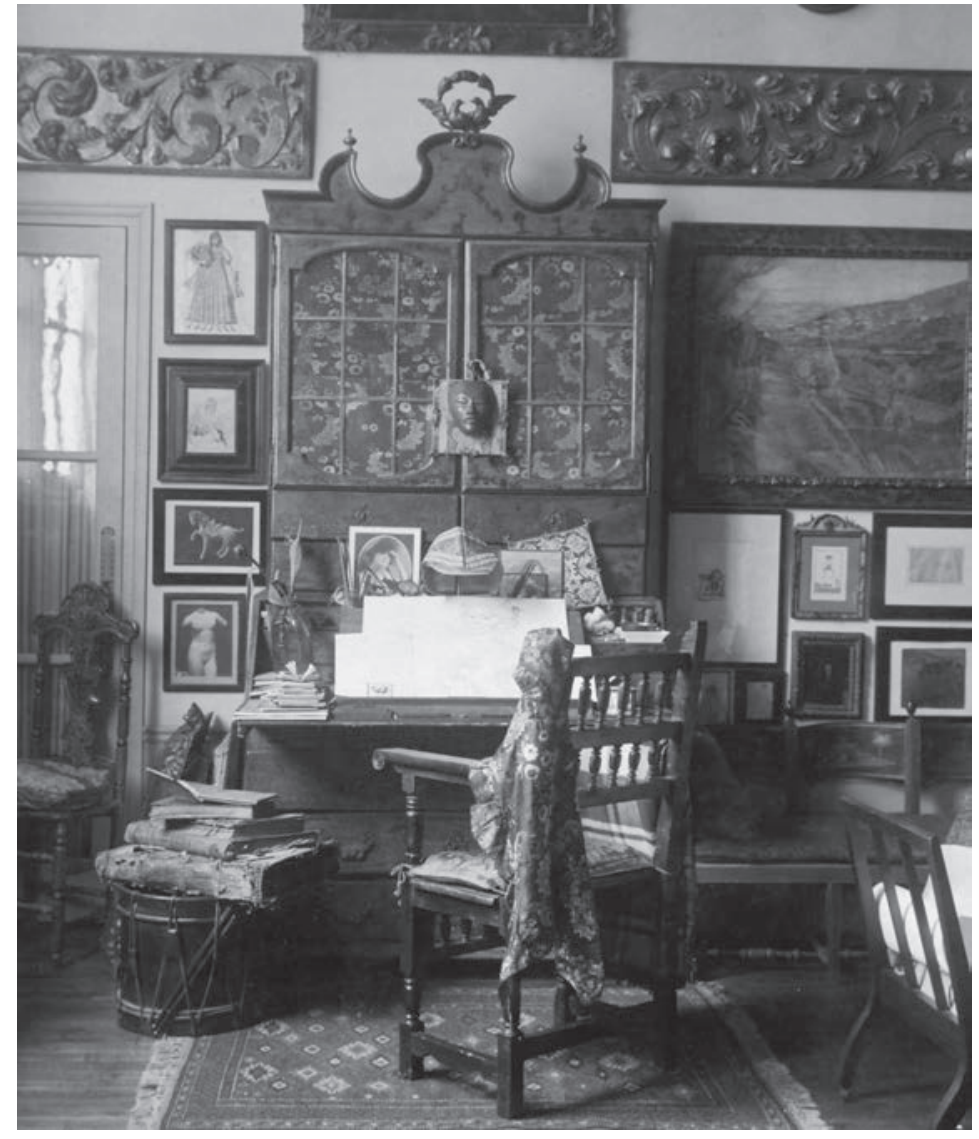

Figura 6.

Fotografia de l'escriptori de Mariano Andreu. Barcelona, Arxiu Documental Mariano Andreu (ADMA), 1925-1935.

L'estudi taller a Biarritz era titllat d'espectacular, perquè quasi estava immers dins l'oceà i tenia un gran finestral de més de set metres d'amplada per cinquanta metres d'alçada. Andreu estava entusiasmat per convertir vil.la Tragaviento en allotjaments d'amics i d'artistes ${ }^{49}$. Volia gaudir amb ells d'aquest gran balcó que ell anomenava «amfiteatre de l'Atlàntic» ${ }^{50}$.

Retirat a Biarritz, es dedicava, com ell mateix deia, a una faceta constructiva que consistia a fer jardins i arquitectures a Tragaviento. Els mobles de París els va col-locar al saló de cent metres quadrats que s'elevava sobre una columna de I2,50 metres d'alçada per 2,50 metres de diàmetre.

\section{L'inventari de les obres subhastades}

Quan Mariano Andreu morí, el seu patrimoni, considerat de riquesa museística (figura 7), passà als hereus i, després de procedir al repartiment dels béns entre la família, el diumenge dia 22 de juliol de I984, a les I 4.30 hores, s'inaugurava la subhasta a vil.la Tragaviento de l'avin- 


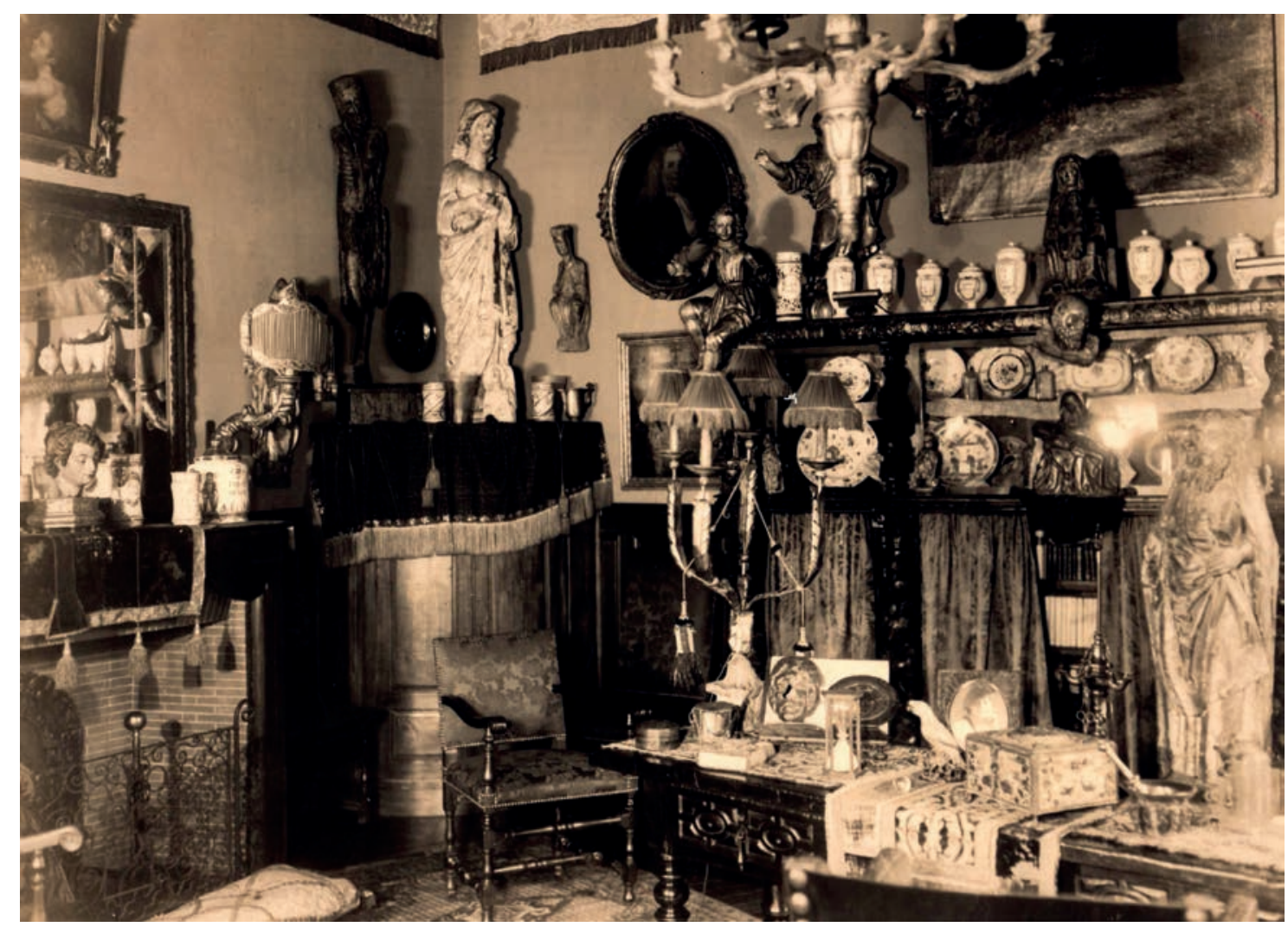

Figura 7.

Fotografia d'una de les estances del matrimoni Andreu al carrer Marbeau. Barcelona, Arxiu Documental Mariano Andreu (ADMA), 1925-1935.

guda de l'Impératrice, número 2i de Biarritz, sota la direcció del commissaire-priseur, maître Jean Carayol de Bayonne ${ }^{51}$. A l'acte, hi participaren M. Kantor, expert en quadres antics, M. $\mathrm{Ph}$. Maréchaux, expert en quadres moderns i M. M. Nazare Aga i Lepic, experts en mobles dels segles XVI, XVII i XVIII. Si, a la primera secció, el nombre d'obres era d'onze, a la segona n'hi havia setanta-dues. La darrera secció era la més nombrosa, amb cent noranta-tres peces dins l'especialitat de mobles.

La casa que durant anys va ser la residència d'estiu del matrimoni Andreu, quan morí la seva esposa, esdevingué la llar permanent de l'artista. Llavors va ser quan la convertí en un espai d'antiquari. Un apropament a les obres subhastades posa en relleu les afeccions del propietari per col-leccionar i restaurar peces d'antiquari destinades a un ús personal i a guarnir les seves obres, alhora que servien de model d'inspiració per a les pròpies creacions. És el cas de les peces abans esmentades: L'esperit del mal (1910), un esmalt amb un marc molt elaborat en retícula entrellaçada; Antíop (1946), un gravat sobre pedra en què l'artista reutilitza un marc d'antiquari que restaura; el tríptic que realitzà per poder transportar l'esmalt Sensus (I910), petit moble que recorda els altars medievals, o bé els nombrosos marcs que l'artista elaborà per singularitzar alguns dels seus olis capdavanters dins del món del mercat de l'art.

Colllateralment, com el mateix artista manifestà, guardava zelosament algunes peces, segurament per nostàlgia a les vivències experimentades al seu entorn. De la llarga llista de pintures, dibuixos i gravats de l'artista, cal destacar-ne aquelles obres que provenien de la seva afecció d'antiquari i colleccionista, especialment pintures del renaixement i del barroc, període del qual s'havia fet un expert. Però potser el més significatiu de tot el que es va subhastar van ser els mobles i els objectes, entre escultures i talles per la seva qualitat, perquè gran part provenien de la col-lecció que havia configurat durant anys i que, per tant, l'havien acompanyat allí on havia viscut. Molt probablement aquest atresorament venia de la il-lusió que l'artista havia forjat de dur a terme el projecte de convertir la vil.la Tragaviento en una escola de formació artística i de coneixements.

L'exposició dividí el patrimoni subhastat en diferents categories, tal com es desprèn del catàleg. A la de «Tableaux anciens», numerada de l'I al ıo, s'hi van incloure els olis intitulats Portrait de deux hommes (escola de Goya); Group de musiciens et danseurs dans un paysage (escola espanyola del segle XVIII); Vierge et enfant (escola italiana del segle XVII); quatre paysages ani- 
més (escola francesa (?) del segle XVIII); Portrait d'un ecclésiastique (sense atribuir); David et Goliath (escola espanyola de finals del segle XVII); Nature morte de fleurs et fruits (escola espanyola de finals del segle XVII); La diseuse de bonne aventure (escola espanyola del segle XVII), i La collation (escola espanyola del segle XVII), a més de vint-i-tres aquarel-les (escola espanyola d'inicis del segle XIX) i cinc panneaux de décoration dans un cadre (sense atribuir).

Dins la classificació d'obres realitzades per Andreu, a l'apartat «Peintures», numerat de l'i a la 40, s'han considerat rellevants per a aquest estudi aquelles en què l'artista elaborà un marc sumptuós, amb la qual cosa mostrà la seva habilitat d'artesà i d'artista creador, com al número I 5 , L'écuyère. A la secció de «Dessins", del número 4I al 65, el número 4I, Gavotte de Prokofieff, i el número 45, Coiffure pour Diana Wynyard. A l'apartat "Objets divers, sculptures...», del número 73 al 82 , corresponen els objectes creats per Andreu, entre els quals cal destacar el número 78, Coffret en émaux clisonnés, el número 80, Miroir, i el número 8I, Lampadaire, per la diversitat de materials emprats, a més dels plats, les màscares i les petites escultures. En totes aquestes obres, hi podríem trobar un referent formal a les peces vistes o adquirides en subhastes, encants, galeries i antiquaris per l'artista com a motiu o base d'inspiració.

Els apartats «Sculptures, bois dores, bibelots...», del número ror al 200, i l'anomenat «Sièges et meubles», del número 20 I al 293, són els que resumeixen ben clarament l'afecció de l'artista per visitar aquests tipus d'establiments. La llarga llista d'objectes, escultures i mobles representa una part del que Mariano Andreu va arribar a posseir i negociar, ja que cal tenir present que els familiars n'havien arreplegat algunes, al marge d'aquelles peces que el mateix artista havia regalat o venut. D'aquesta relació del catàleg, en tornaríem a destacar el llit i l'escriptori que l'artista utilitzà diàriament com a objectes excepcionals ${ }^{52}$, però també cal fer esment d'altres pel refinament del treball emprat, qualificades de veritables peces d'antiquari, tal- ment com són definides al catàleg. Per exemple: la número 217, «Paire de fauteuils à haut dossier orné de pommeaux de cuivre, acooudoirs a volutes moulurées, piètement à entretoise orné de volutes feuillagées» (Espanya, segle XVIII); la número 256, «Armoire basse en moyer mouluré de panneaux rectangulaires partiellement incrustés d'étoiles en os; base en doucine reposant sur des pieds griffes» (Espanya, segle XVII); la número 258 , «Beau coffre en chêne à façade sculptée de fleurs et feuillages entourant des panneaux moulurés» (Espanya, segle XVIII); la número 259, «Meuble scriban en chêne mouluré ouvrant à quatre portes et un abattant; décor de cannelures et guirlandes de perles. Petits pieds cambrès» (segle XVIII); la número 260, «Table de chageur enplacage de noyer et filets de bois clair; elle ouvra à un compartiment central et deus tiroirs latéraux, piètement finement tourné à enretoise» (sense datar), i la número 264, «Table rectangulaire à deux tirettes, à piètement tourné réuni par une entretoise; plateau enserrant une plaque d'ardoise» (Suïssa, segle XVIII).

D'altra banda, el fet que els especialistes participessin en tableaux anciens, en tableaux modernes $\mathrm{i}$ en mobles dels segles XVI, XVII i XVIII en la catalogació de les peces és una prova més de l'interès que suscità entre els entesos aquesta subhasta per la qualitat de les peces.

A la mort d'Andreu, s'assenyalava que una figura com ell era difícil que tornés a existir, per la gran quantitat d'obra que havia realitzat en diferents disciplines artístiques, inclosa la de decorador, per la seva entrega a l'art i perquè sempre va ser un gran senyor, amb bon tracte amb la gent. Tothom el va conèixer i ell mateix també coneixia tothom dins d'un món particular que va configurar i que va saber plasmar ${ }^{53}$. Veritablement, Andreu va viure dins la seva obra, no sols per les construccions i les visions que va ser capaç d'idear, sinó també perquè va reconstruir un entorn en les cases on va residir que recordava diferents períodes històrics $\mathrm{i}$ tendències artístiques. Un món màgic i de faula que trobà i que imaginà a la casa paterna, com a punt de partença de totes aquelles on es va establir. 
1. Andreu sempre manifestà que fou a través de l'estudi dels grans mestres als museus com es va formar en la pintura (S. GASCH (1953), L'Expansió de l'art català al món, Barcelona, Impremta Clarasó, p. 75, i D. Bourdet (1958), «Mariano Andreu", La Revue de Paris "Images de Paris» (novembre), p. 140-142).

2. Arxiu Documental Mariano Andreu (Barcelona), a partir d'ara, ADMA 1939-1959. Empreintes (memòries inèdites de l'artista), p. $128-130$.

3. «L'Exposició Andreu», crònica publicada a La Veu de Catalunya, 176 (1 de maig de 1913), p. 2, i «En Mariàn Andreu», crònica publicada a La Veu de Catalunya, 178 (15 de maig de 1913), p. 5.

4. ADMA 1912-1913. Cartes d'Andreu a Filo (futura esposa) escrites des del 27 de novembre de 1912 fins a la primavera de 1913.

5. L'any 1913 exposà al Neue Kunst Hans Goltz de Munic i se li encarregaren els dissenys de les operetes Odyssens o Le retour d'Ulysse, de Jacques Offenbach, i Mikado, d'Arthur Sullivan, que es representarien al Künstler Theatre durant el festival d'estiu de la capital bavaresa.

6. V. SolÉ De Sojo (1913), «Hablando con Mariano Andreu», El Día Gráfico (25 de novembre), p. 7.

7. Vell $i$ Nou, any I, 1-2 (13 de març de 1915).

8. Vell i Nou, any I, 11 (15 d'octubre de 1915), p. 14. ADMA 1930. Fotografia de la residència Andreu a París on figura la peça.

9. AFCMR 1965. Carta d'Andreu a Manuel Rocamora, 19 de febrer de 1965.

10. La Vanguardia (30 de maig de 1970), p. 47.

11. AFCMR 1952. Carta de Mariano Andreu a Manuel Rocamora, París, 29 de novembre de 1952.

12. AFCMR 1952. Carta de Mariano Andreu a Manuel Rocamora, París, 22 de desembre de 1952. Tot i que la correspondència entre Andreu i Rocamora és prou descriptiva, no hem pogut identificar els quadres del Museu del Prado en el moment de publicar aquest article, un tema que resta pendent d'investigar.

13. ADMA 1957. Carta de Mariano Andreu a la seva dona, Londres, 27 de maig de 1957.
14. L'any 1953 n'era acceptat com a membre, i l'any 1958, com a acadèmic amb tots els honors.

15. Els textos foren recopilats a l'edició Velázquez son temps, son influence per D. Angulo IÑIguez, «Le tricentenaire de Vélasquez», Gazette des Beaux Arts, La Chronique des Arts, suplement, número 1108-1109 (maig-juny de 1961), p. 1-4, i la valoració del seu discurs, per E. Garcia-Portugués (2007), «El reconeixement artístic de Mariano Andreu en el nostre país», Butlletí de la Reial Acadèmia Catalana de Sant Jordí, XXI, Barcelona, p. 101-116.

16. G. Díaz-Plaja (1960), «Al filo del estío: Visitas a Mariano Andreu", La Vanguardia (4 de setembre de 1960), p. 9.

\section{Archivo Casa Museo}

Tomás Morales (Las Palmas de Gran Canaria), a partir d'ara ACMUTM. Carta d'Andreu a Néstor del mes de maig de 1910 (P. Almeida Cabrera (1987), Un Canario Cosmopolita, Las Palmas de Gran Canaria, Real Sociedad Económica de Amigos del País, p. 59, i P. Almeida CABRERA (1990), «Perfil biográfico de Néstor», El simbolismo en Europa, Las Palmas de Gran Canaria, Centro Atlántico de Arte Moderno, p. 168. Mariano Andreu exposava el quadre $R e-$ trato de un desconocido a la sala viII, Pintura de Leonardo Alenza («Retrato a un desconocido», Exposición de Retratos y Dibujos Antiguos y Modernos (1910) (catàleg de l'exposició), Barcelona, Ajuntament de Barcelona, Imp. de Heinrich y Cia. en Comandita, maig de 1910, núm. 18, sala viII, pintura, p. 52).

18. ACMUTM. Carta de Mariano Andreu a Néstor, Barcelona, 3 d'abril de 1910.

19. Dissortadament, dels regals que realitzaren els presents a l'homenatge a Rusiñol al Museu Municipal de Sitges, només en tenim les dades que es publicaren a la notícia: «Sitges per en Rusiñol: Impressions d'una festa», L'Esquella de la Torratxa (24 de gener de 1913), p. 69. D'aquest homenatge, en sorgí l'encàrrec que l'alcalde de Sitges va fer a Andreu de realitzar-ne la placa (1913) que es conserva al Museu Cau Ferrat de Sitges (núm. inv. 31286). Per a més informació, consulteu la publicació E. Garcia-Portugués (2016), «Mariano Andreu i l'homenatge de Sitges a Santiago Rusiñol», L'Esmalt, 12 (desembre), p. 10-12.
20. La Veu de Catalunya, pàgina artística número 172, Barcelona (3 d'abril de 1913).

21. Oscar Wilde (2014), Las artes y el artesano, traducció de Carlos García Simón, Madrid, Gadir Editorial, p. 20.

22. El cofre realitzat per Andreu fou presentat al catàleg amb el títol Coffret enémaux cloisonnés, à decor de volatiles et de têtes, supporté par des mains en bronze (núm. 78). També s'hi subhastaren alguns dels plats decoratius, números 77 i 79 (ADMA 1987. Catàleg de l'exposició de la subhasta).

Aclariment: el senyor Jean Carayol, un expert de Baiona, fou el comissari i l'encarregat de realitzar una edició de pocs exemplars del catàleg de les peces que hi van ser subhastades. Els exemplars anaven destinats als galeristes i als col-leccionistes que van assistir a la licitació. Tal com s'indica mès endavant, el catàleg no representa tot el que va colleccionar Andreu, però sí que n'és prou representatiu, atesa la quantitat i la varietat de les obres subhastades després que els hereus i la família s'adjudiquessin part del seu patrimoni. L'Arxiu Documental Mariano Andreu (ADMA) conserva un exemplar a través del qual hem pogut identificar algunes de les obres.

23. En són un exemple: Coffret oblong en bois laqué corail et or (Espagne XVIIIe siècle), núm. 137; Plat décoré d'un vas et papillon i Plat décoré d'un vase et de plumes de paon (Delft XVIIe siècle), núm. 143 i 144, i Plat rond à décor floral bleu et blanc (Chine XVIIIe siècle), núm. 145 (ADMA 1987. Catàleg de l'exposició de la subhasta).

24. Tant l'esmalt com aquesta obra no van sortir a subhasta $i$ van passar als hereus de l'artista.

25. Aquesta obra s'exhibeix al Museu del Disseny de Barcelona (MADB 135.254).

26. L'obra fou subhastada amb el número 41 (ADMA 1987. Catàleg de l'exposició de la subhasta).

27. L'obra fou subhastada amb el número 15 (ADMA 1987. Catàleg de l'exposició de la subhasta).

28. L'obra fou subhastada amb el número 80 (ADMA 1987. Catàleg de l'exposició de la subhasta).

29. L'article, publicat per Un Ingenio de esta Corte a Blanco y $\mathrm{Ne}$ gro, Madrid, 11 de març de 1928, destacava la fantasia i la delicadesa de la producció, per exemple, de 
l'estàtua eqüestre col-locada dins d'una urna de cristall, el cavall de la qual estava confeccionat utilitzant tiretes de paper, una tipologia que recordava els estudis de Leonardo da Vinci. Consulteu E. Garcia-Portugués (2015), «Mariano Andreu: Del Don Juan del Ballet de Gluck a la versió teatral de Montherlant», EMBLECAT: Revista de l'Associació Catalana d'Estudis d'Emblemàtica. Art i Societat, 4, Barcelona, Emblecat Edicions, p. 89-109 i 104 il-lustració.

30. M. SAndoval (1935), «Las actividades artísticas de París: El pintor Mariano Andreu», Revista Ford, Barcelona (octubre), p. 369; L. Cheronnet (1935), «Les miroirs encadrés» [«Les glaces encadrées de Mariano Andreu»], Art et Décoration, París (maig de 1935), p. 199, i A. SAGE (1937), «Miroirs d'Aujourd'hui», Le Figaro Illustré (febrer de 1937), p. 32-35.

31. Oscar Wilde (2014), Las artes..., op. cit., p. 13.

32. ADMA 1935. Catàleg de l'exposició. Hi participà el Comitè de Patronatge format per M. Huisman (Directeur des Beaux Arts), M. Dézarrois (Conservateur du Musée du Jeu de Paume), M. JeanLouis Vaudoyeer (Conservateur du Musée Carnavalet) i M. Henri de Régnier de l'Académie Française.

33. Denis Bourdet (1958), La Revue de Paris..., op. cit., p. 140 142.

34. Carta d'Ignasi Mallol a Francesc Vayreda s. d. (fotocòpia proporcionada per Miquel Àngel Codes Luna). Abans de Mallol, l'estudi l'ocupà el pintor Miquel Farré $(\mathrm{La}$ Vanguardia, 3 d'abril de 1976).

35. ADMA 1910. Fotografia: Mariano Andreu a l'estudi de Roger de Llúria.
36. Aquest gran bodegó fou llegat als hereus d'Andreu. Sobre aquests referents barrocs en la paleta d'Andreu, consulteu l'estudi E. Garcia-Portugués (2007), «El reconeixement artístic de Mariano Andreu en el nostre país», Butlleti de la Reial Acadèmia Catalana de Sant Jordí, XXI, Barcelona, p. 101116. Alguns d'aquests bodegons foren subhastats a Biarritz (ADMA 1978. Catàleg de l'exposició de la subhasta).

37. Monte-Cristo (1928), «Casas españolas en París: La del pintor Andreu", Blanco y Negro, Madrid (19 de febrer de 1928), p. 54-56, i Blanco y Negro (11 de març de 1928), p. 57-58.

38. Denis Bourdet (1958), La Revue de Paris..., op. cit., p. 140.

39. P. Espil (1968), «Mariano Andreu: 80 ans le 7 novembre», SudOuest (5 de novembre).

40. «La Casa del Sr. Marian Andreu», D'Ací i d'Allà, XVII (127), Barcelona (juliol de 1928), p. 252-256.

41. ADMA 1925-1935. Fotografia del seu estudi taller publicada a E. Garcia-Portugués (2007), Mariano Andreu (catàleg de l'exposició), Madrid, Galería José de la Mano.

42. ADMA 1987. Catàleg de l'exposició de la subhasta.

43. D'Ací i d'Allà, op. cit. ADMA 1939-1959. Empreintes.

44. Denis Bourdet (1958), La Revue de Paris..., op. cit., p. 140142.

45. Després d'una breu biografia de l'artista i unes ratlles a la donació del Crist, descrivia com era la vil.la (l'articulista s'identificava només amb les inicials) F.L. (1969),
«La Cathédrale de Bayonne s'est enrichie d'une oeuvre d'art réalisée et offerte par Mariano Andreu», Basque Eclair, 4 de novembre). Sobre les obres de l'època blava de Picasso esmentades a la premsa, només en tenim aquesta notícia. La família en desconeix l'existència i, al catàleg de les peces que se subhastaren, no hi surten relacionades. Molt diferent és el quadre de Velázquez heretat per la família (figura 4), un bodegó barroc que els experts han atribuit a l'escola sevillana del segle xvir sense descartar-ne definitivament l'atribució a Velázquez o a un artista del seu entorn.

46. P. Espil (1976), «Avec Mariano Andreu, Biarritz a perdu un grand ami et un grand artiste», Sud-Onest, 2 (abril).

47. Sud-Ouest, 5 de novembre de 1968.

48. Denis Bourdet (1958), La Revue de Paris..., op. cit., p. 142.

49. Sempronio (1964), «Mariano Andreu abandona París...», Destino (22 de febrer), p. 43. A l'entrevista, l'artista comentava el seu projecte d'obrir una escola a Biarritz.

50. AFCMR. Carta d'Andreu a Manuel Rocamora (París, 6 de desembre de 1963).

51. Pel nombre de peces exhibides, l'esdeveniment continuà l'endemà (ADMA 1984. Catàleg de l'exposició de la subhasta).

52. Números 276 i 245, respectivament (ADMA 1978. Catàleg de l'exposició).

53. «En la muerte de un gran artista. Recuerdo de Mariano Andreu», La Vanguardia, Barcelona (3 d'abril de 1976). 
